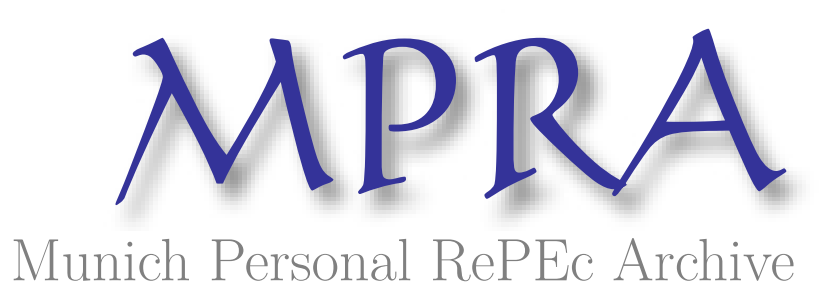

\title{
How Elitism Undermines the Study of Voter Competence
}

\author{
Lupia, Arthur
}

2006

Online at https://mpra.ub.uni-muenchen.de/349/

MPRA Paper No. 349, posted 09 Oct 2006 UTC 


\section{Arthur Lupia}

HOW ELITISM UNDERMINES THE STUDY OF VOTER COMPETENCE

ABSTRACT: A form of elitism undermines much writing on voter competence. The elitist move occurs when an author uses a self-serving worldview as the basis for evaluating voters. Such elitism is apparent in widely cited measures of "political knowledge" and in common claims about what voters should know. The elitist move typically limits the credibility and practical relevance of the analysis by leading writers to draw unreliable conclusions about voter competence. I propose a more constructive way of thinking about what voters know. Its chief virtue is its consistency with basic facts about the relationship between information and choice.

Critical Review 18 (2006), Nos. 1-2. ISSN 0891-3811. www.criticalreview.com

Arthur Lupia, Department of Political Science, 4252 Institute for Social Research, University of Michigan, Ann Arbor MI 48109, thanks Robert Huckfeldt, Yanna Krupnikov, Adam Seth Levine, Jesse O. Menning, Jasjeet S. Sekhon, and Gisela Sin for advice on previous versions of this manuscript. 
Many people write about voter (in)competence. The topic is especially tempting after an author's favored side loses an election or public-policy battle, for they can attribute their losses to voter ignorance (e.g., Herbert 2004). Other evaluations of voter competence arise when elections approach. These occasions prompt claims about "what informed voters ought to think about" when making political choices. Some of these claims are ideological in nature: they assert that a set of ideas with which they and their peer group agree should be privileged in political decision-making. One problem with such claims is that ideas in question need not be consistent with the self-interest of the voters who are being advised to become "informed" in a certain direction or consistent with the broader interests of the society in which these voters live.

Other critiques of voter competence are more academic in nature. Many use data from election surveys administered by scholars. While most survey items query respondents” opinions, others--“political knowledge" questions--yield responses that can be checked against documented facts. An example of such a question is: "Who is the Chief Justice of the U.S. Supreme Court?” At almost all moments in the era of survey research that began after World War II, this question has had a discrete answer. At the time of this writing the answer is John Roberts.

Many people do not give correct answers to standard "political knowledge" questions. Some respondents provide incorrect answers. Some say they "don't know." Others just don't respond at all. Academic writers have used these responses to generate broad conclusions about voter competence. Stephen Earl Bennett (1988) and Ilya Somin (2004), for example, are among those who use political knowledge scales (the sum of the number of correct responses to these questions) to conclude "that about one-third of 
respondents are 'know nothings' possessing little or no politically relevant knowledge" (Somin 2004, 8).

In such conclusions, a form of elitism emerges. To see why such claims are elitist, ask yourself two questions. First, what benefit does a randomly selected citizen draw from knowing something like the name of the Chief Justice? Second, what benefit does society receive when a randomly selected individual can recite this fact? Before answering these questions, a moment of introspection may be instructive. I suspect that most of the people who will read this article are social scientists, journalists, lawyers, students, or other people with a deep interest in politics. In any of these roles, we have tasks to accomplish. For example, as a political-science professor at a major research university, I am expected to teach classes, to conduct research, and to mentor others. To accomplish these tasks, I must know certain things. Since I occasionally publish in law journals and often give lectures and conduct research on topics for which the Supreme Court is relevant, the name of the Chief Justice happens to be one of the things that it is beneficial for me to know. I would be embarrassed not to know it. Indeed, if I were revealed not to know such a thing in a public forum, my reputation might suffer. Given my impression of who will read this article, I suspect that something similar is true for you, the reader. And so it is for many "political knowledge" questions. Their answers are things that you and I are expected to know, given our occupations or interests.

Such characteristics make us unrepresentative of the general population. We have unusual interests and obligations. It is not necessarily the case that the information that we feel that we must know has the same value to others. 
In theory, those who write about voter competence might recognize the differences between their interests and the interests of the people whom they study. In practice, they tend to set these differences aside. Most political-knowledge questions are not derived from a replicable or transparent logic about how their answers bear on a voter's ability to make decisions of a particular quality in the voting booth. Instead, the questions are generated by a worldview that is shared by a select set of academics, journalists, and politicos, but few others. Political-knowledge questions test information that academics, journalists, and politicos value. The answers to these questions help them accomplish important tasks. The elitist move is to assume that these questions have a similar value to citizens whose societal responsibilities can be very different than their own. When writers make this elitist move, they can switch from facilitating outcomes from which the voter or society will benefit to imposing on citizens a worldview whose relationship to such outcomes is speculative, at best.

While writers are quick to categorize citizens as "ignorant" because they cannot answer typical political knowledge questions, they are slow to ask whether the questions themselves are part of the problem. Lest this judgment seem too harsh, it is worth pointing out that many of the questions now regularly used and cited by votercompetence writers are legacies of eras in which scholars knew far less about the relationship between information and choice than researchers know today (Lupia 2005b). If a goal of writing about voter competence is to increase the likelihood that voters make the same kinds of decisions they would have made if they had more information, then analysts should reconcile their claims with modern research on how various kinds of information relates to the quality of vote choices. 
For the academic and popular literatures on voter competence, a change in practice is sorely needed. Measures of competence that correspond more closely to the kinds of decisions voters actually face can yield social benefit. But until votercompetence writers improve their own skills in assessing others, they limit their ability to participate in the delivery of such benefits and may, in fact, be making matters worse.

In what follows, I first evaluate common political-knowledge questions and scales. I find that these items reflect a worldview in which many journalists and political scientists have a valid professional interest. Less clear is whether individuals or societies are better off when the mass public spends time and effort learning how to act in accordance with this worldview (i.e., to learn the answers to common politicalknowledge questions). Next, I offer a strategy for developing voter-competence measures that are more consistent with basic facts about how information relates to choice. In each case, I contend that examinations of voter competence that are based less on elitist speculation about what voters should know will strengthen our collective ability to understand and improve voter competence.

\section{The Limited Value of Current Political-Knowledge Questions}

Most citizens spend very little time attending to the details of politics. This makes some analysts suspicious of what voters have in mind when they vote. Since analysts cannot observe voters' thoughts directly, they often turn to political-knowledge questions that are much like the quizzes administered in civics classes. They reveal who can respond correctly to inquiries such as "What is the political office currently held by Dick Cheney?" 
Many citizens have a difficult time answering these questions. A 1996 book by Michael Delli Carpini and Scott Keeter provides a comprehensive study of the matter. It covers many decades and surveys. Analysts regularly use such data to conclude that voters are ignorant, unsophisticated, or incompetent. (Delli Carpini and Keeter draw a more nuanced conclusion, focusing on the differences between groups.) While such data may be useful for other purposes, their relevance to voter competence is quite limited.

To see why, let's define competence. I define competence as the ability to accomplish a task. If a person who knows facts $\mathrm{X}, \mathrm{Y}$, and $\mathrm{Z}$ can successfully accomplish task $t$, then it is conventional to call this person competent at $t$. This definition is a technical one, analogous to definitions used in research on expertise and competent performance in fields such as cognitive science and the study of artificial intelligence (see, e.g., Newell 1990).

Given this definition, how should voter competence be measured? I will follow James H. Kuklinski and Paul J. Quirk's framework:

There are four principal conceptual components in any evaluation of performance. First, one must identify the task that the actor is asked to undertake. ... Second, one must state a criterion by which the performance is to be evaluated - that is the property or attribute that is taken to constitute the quality of performance. Third, one must recognize at least one empirical indicator of that criterion. Finally, to categorize levels of performance, one must identify standards with respect to the indicator. Standards map levels of the indicator 
onto a set of evaluative categories: satisfactory or unsatisfactory;

very good, good, fair, poor and the like. (Kuklinski and Quirk

2001, 287, emph. in original.)

Here, I will examine the relationship between a voter's ability to accomplish an electoral task and the ability to answer certain kinds of survey questions. To keep this essay compact, I will constrain my discussion to technical aspects of the relationship. For example, while I will examine indicators of whether a voter can cast a vote that satisfies a particular criterion (such as whether it is the same vote she would have cast if she had all relevant information available at the time of her choice), and while such criteria are inherently normative, I will not engage the underlying debate about whether the criterion I use for the purposes of example match some of the normative criteria for voting that others have proposed. Elsewhere, I address this complex debate in greater detail (Lupia 2005b).

\section{Helpful vs. Necessary Political Knowledge}

In thinking about how to measure voter competence, it is crucial to distinguish between knowledge that may be helpful and knowledge that is necessary for competent task performance. To see how the two can be confused, consider the following problem. A voter knows a set of 26 facts that we can label A-Z. Suppose that knowing such facts allows the voter to accomplish a particular task, $t$, competently, where the task in question is to cast a vote for the option that best fits a set of normative requirements to which we have previously agreed. This information, A-Z, is sufficient for casting a 
competent vote. But an important question for how we evaluate voter competence is, Is knowing A-Z necessary for a competent vote?

To answer the question about necessity, we must ask whether there is a different set of facts, perhaps even a subset of facts A-Z, that also allows the voter to accomplish $t$ ? If the answer is no, then knowledge of every fact from $\mathrm{A}$ to $\mathrm{Z}$ is necessary for the voter to choose competently. In such a case, we can assess the voter's political competence reliably by quizzing her about A through Z--as with the political-knowledge tests on which so many analysts base their judgments of voter incompetence. If we find her deficient in her knowledge of even one of these facts, we can accurately judge her incompetent at task t. If we want to increase her competence at this task, moreover, we know that a precondition of success is providing her with the knowledge of all such facts about which the quiz reveals her ignorance.

The problem with this approach to assessing voter competence is that it is validity depends on establishing that facts A-Z are necessary for competence: i.e., that knowledge of no subset of these facts, or alternative set of facts, would suffice for task t to be accomplished. However, if facts other than the full set A-Z are sufficient for citizens to accomplish $\mathrm{t}$, then knowing $\mathrm{A}-\mathrm{Z}$ cannot be a necessary condition for competence at $\mathrm{t}$. Thus, merely demonstrating that a voter does not know these facts may reveal little or nothing about her competence in the voting booth.

Nevertheless, many contemporary analysts base many claims about voter incompetence not only on common political knowledge questions, but also on findings such as those of Philip E. Converse ([1964] 2006), who discovered that only 10 percent of the public could define the meaning of "liberal" or "conservative," and who had earlier 
argued that an even smaller percentage of the public actually used such ideological categories in evaluating candidates and parties (Campbell, Converse, Miller, and Stokes 1960). Drawing broad conclusions about competence from either kind of evidence requires the premise that concepts such as "liberal" and "conservative" are necessary for voting competently (e.g., voting as one would if they had all available information). But I am not aware of any such evidence ever having been presented. While the ideological terms are helpful to some analysts, they need not be valuable to others. Indeed, if there are multiple informational pathways to a competent vote (e.g., interest- group endorsements, effective heuristics, etc., lead a voter to cast the same vote as she would have if better informed.), then voters need not use the same terms that political elites use.

Voters can be ignorant of ideological terms or the Chief Justice's name and still make competent choices in the voting booth. For voters, alternative terms, such as "Democrat" and "Republican," or "liked by people I respect" and "disliked by people I respect," can produce the same choices that voters would have made if they were walking political encyclopedias. Observing that survey respondents answer questions about ideological labels or common political knowledge incorrectly means nothing more, in itself, than that the respondents cannot (instantly) recall terms that political scientists and journalists know well. Broad claims about what such observations tell us about voter competence are of dubious credibility. 


\section{All Politics Is Not Federal}

When I first made such arguments to colleagues, I was assured that recent work established the validity of political-knowledge questions. And, indeed, there is work that claims to do this.

Delli Carpini and Keeter (1996, 151-52; see also ibid., 329-33) follow previous researchers by using factor analysis to defend the assumption that "a scale with a limited number of factual items, if carefully constructed, can be used to approximate what citizens know more generally about politics." I agree that these statistics show that people who are good at answering some "political knowledge" questions tend to be good at answering other questions of the same ilk. It is not, however, clear that such tendencies imply anything about a voter's competence in the voting booth, or her political competence considered more generally.

To see the problem with such claims, consider analogous debates about the measurement of intelligence. In The Mismeasure of Man, Stephen Jay Gould argues that intelligence cannot be meaningfully abstracted as a single number. In examining whether factor analysis supports the validity of such numbers, Gould $(1996,48)$ maintains that "the key error of factor analysis lies in reification, or the conversion of abstractions into putative real entities." In particular, he shows the flaws in attributing too much to the first principal component in a factor analysis--the same type of statistic upon which prominent "political-knowledge" scholars base their claim of validity:

The first principal component is a mathematical abstraction that can be calculated for any matrix of correlation coefficients; it is not a 
"thing" with physical reality. Factorists have often fallen prey to a temptation for reification - for awarding physical meaning to all strong principal components. Sometimes this is justified; I believe that I can make a good case for interpreting my first pelycosaurian axis as a size factor. But such a claim can never arise from the mathematics alone, only from additional knowledge of the physical nature of the measures themselves. For nonsensical systems of correlation have principal components as well, and they may resolve more information than meaningful components do in other systems. A factor analysis for a five-by-five correlation matrix of my age, the population of Mexico, the price of Swiss cheese, my pet turtles' weight, and the average distance between galaxies during the past ten years will yield a strong first principal component. This component --since all the correlations are so strongly positive--will probably resolve as high a percentage of information as the first axis in my study of pelycosaurs. It will also have no enlightening physical meaning whatsoever. (Ibid., 280.)

The dependent variable being measured by political-knowledge scales--voter "competence"--is akin to the general "intelligence" of which Gould spoke. Its validity depends on "additional knowledge of the physical nature of the measures themselves." Gould's challenge to users of political-knowledge scales is to locate, in the questions 
themselves, a credible theory of information and choice that confers, upon the results of a factor analysis, any relevance that goes beyond simple reification.

This means that it matters how political-knowledge questions are chosen. To validate a scale, it must be compared to something that is itself considered a valid measure of the underlying concept. We would not, for example, claim that a politicalknowledge scale had been validated if we found that responses to these questions were highly correlated with shoe size, because shoe size is not considered a valid measure of political knowledge. Similarly, we should give weight to the factor-analytic finding of a correspondence among responses to political-knowledge questions only if at least some of those questions are themselves the consequence of a well-thought out, transparent, and replicable process that builds from sound analysis of what kind of knowledge is necessary for politically competent choices.

So from what theoretical perspective do contemporary political-knowledge questions come? The answer is not encouraging. As Delli Carpini and Keeter $(1996,299)$ put it, "the selection of specific items remains fairly subjective, guided by the goals of the research and influenced by factors not easily quantified."

With this information in hand, the question becomes, "What are the goals and factors that produced the questions?" Elitism is a large part of the answer. To see how, note that political scholars and journalists who have reached the pinnacles of their respective fields tend to write for prestigious outlets with relatively large national audiences. The lure of a national audience induces ambitious journalists and scholars to focus far more on presidential elections than local ones, far more on congresspersons than on state or local legislators, and far more on federal bureaucrats than their counterparts at 
other levels of government. Without minimizing the importance of federal activities, it is important to recognize that they constitute but a handful of all of the politically relevant actions that occur on any given day.

Randomly selected Americans are far more likely to be pivotal in political activities undertaken at the local, parish, or neighborhood levels than they are in any of the national-level activities on which many elite scholars and journalists are fixated. The political influence of most people is far more likely to be felt in decisions made closer to home. Perhaps the masses are more competent than commonly depicted because they realize that investing heavily in the minutiae of federal politics is akin to tilting at windmills.

I know that this suggestion is provocative, but my hope is that it is constructively so. It will, perhaps, produce the objection, "Where would we be if everyone ignored the facts contained in standard political knowledge questions?" It is a good question. A democracy would be a farce if nobody knew basic facts about the operation or character of government. But it requires a grand leap of logic to go from this proposition to the conclusion that everyone, or even most people, ought to be able to answer a set of questions whose origins are "fairly subjective."

Consider, too, an alternative question: Where would we be if everyone knew these facts on which academics and journalists who write about voter competence dote? Would we be so much better off if every American could answer questions such as "Which political party is more conservative?" or "How long is the term of office for a United States senator?" on the spot during a survey interview? 
Knowing such facts has not yet been demonstrated as necessary for competence at common voter tasks. Some scholars claim that such knowledge correlates with political knowledge, more broadly defined. Yet closer inspection reveals that the stated correlations either do not exist; that the correlations are real, but that they are correlations to other political- knowledge questions of "fairly subjective" origin; or that the correlations are to variables such as voter registration and turnout, which are important politically, but are not widely accepted as a valid measures of what people know.

When scholars criticize the mass public for its inability to answer common political-information questions, then, they are basically condemning others for not sharing their federal fixation. This is not to say that elite scholars (and their counterparts in the media) are wrong to have such a fixation. Journalists who work for, or aspire to work for, the nation's most influential news outlets must ultimately learn to produce stories that can be relevant to a national audience. Similarly, the leading political-science journals serve national and international clienteles. Articles that end up in a journal of only local or regional interest tend not to advance the careers of political scientists as much as do articles of national interest.

But most citizens are neither political scientists nor journalists. Perhaps they do not concentrate on the political categories dear to elites because they have figured out that they can't do very much with such concepts, given the very limited opportunities they have to influence national policy. There are substantial differences between the tasks that most voters are asked to perform and the tasks that national journalists and political scientists are asked to perform. Elite attempts to assess voter competence should take these differences into account. 


\section{The Sufficiency of Proxies and the Superfluousness of More}

There is a different way of assessing voter competence, one that starts with understanding the difference between knowledge that is necessary for competence at socially-valuable tasks and knowledge that is merely helpful to political elites but perhaps of limited use to others.

Two crucial aspects of this understanding are that many kinds of information can lead a voter to reach the same conclusion; and that we should evaluate a voter as competent regardless of how she reaches a conclusion, as long as it is the conclusion she would have reached had she been aware of the best available information. It is her performance that counts, and there can be many informational paths to success. A voter may not need to remember everything she has heard about the topic (see, e.g., the discussion of online processing of political information in Lodge and Taber 2000). Moreover, she need not even have been exposed to, let alone carefully thought about, every available piece of information. For her, a subset of available information may suffice (Popkin 1991). And if the information on which she acts suffices, additional information is not necessary to increase her competence with respect to this task.

For many choices, the amount of information that can be sufficient to cast a competent vote is limited by a voter's range of choices. Consider, for example, the case where a voter is asked to endorse or reject a referendum. In such cases, voters are not allowed to draft amendments. They are not allowed to approve only parts of a referendum. They are restricted to a simple yes or no response. Even if a ballot measure is very technical, the voter's choice is either the measure or the status quo. Once one has 
information sufficient to distinguish which of these two alternatives is "better," it is impossible for additional information to be necessary to cast a competent vote.

The number of ways that a voter can make a competent inference determines whether any particular fact is necessary for competence. If there is one and only one fact that will allow a voter to make a correct determination about whether the referendum is better or worse than the status quo, then the fact is necessary. In many cases, however, there is more than one such fact. Interest groups, politicians, newspapers, and other public entities often offer public endorsements of particular ballot measures, any one of which may suffice as a proxy for detailed knowledge. Consider, for example, a referendum on gun control that both one's local newspaper and the National Rifle Association (NRA) oppose. For people who know that their stance on all such issues parallels that of the newspaper or the NRA, either endorsement can serve as an effective substitute for information such as the actual text of the referendum. It can lead them to cast exactly the same vote. In the same way that drivers use the trajectory of oncoming headlights to draw accurate inferences about the future locations of other cars, and consumers use brand names to draw accurate inferences about particular qualities of many consumer goods, citizens can use endorsements to draw accurate inferences about important attributes of political phenomena.

Such proxies are not just present in referendums. Voters' continuing reliance on proxies such as party labels plays a similar role in candidate-based elections. In almost every aspect of our lives, we use proxies such as brand names, the advice of others, and regularities of nature to come to quick--and often reliable--conclusions about the consequences of our actions. It is no more reasonable to expect voters to have detailed 
knowledge of political matters where such proxies are available as it would be to expect Mercedes buyers to have an auto mechanic's understanding of exactly how DaimlerChrysler produces cars that perform well. Even professional legislators regularly use endorsements from their research staff and party leaders as substitutes for reading every word of every proposed law themselves. When citizens can use endorsements to cast the same vote that they would have cast if they had better information, the finding that citizens cannot recall minute legislative details is irrelevant. Instead, we should ask: "What proxies suffice for competent voting?"

Scholars who offer blanket criticisms of the quality of heuristic decision making often overlook the notion of sufficient information. An endorsement offered by a newspaper, the NRA, or the Democratic party means nothing in isolation, but if people can use such knowledge (i.e., prior knowledge of the NRA or the newspaper's political stances) to draw correct inferences about the implications of such endorsements for their own political choices, such an endorsement can suffice for competent decision making.

insert Figure 1 about here

Figure 1 depicts the kind of information needed for the voter to make a reliable inference in such cases. One side of the triangle is the relationship between the chooser and the endorsement (proxy). The second side is the relationship between the proxy and the choice. The third side is the relationship between the chooser and the choice. The proxy can be necessary for the person's competence (i.e., it is necessary if the chooser is 
to make a reliable assessment of the triangle's third side) only if they are incompetent initially. The proxy is sufficient if the chooser has enough information about the first two sides of the triangle. This includes information about the relationship between the chooser and the endorser, in the case of that type of proxy; as well as information the relationship between the endorser and the consequence of the choice. An endorsement from a complete stranger is not typically sufficient because the person is uncertain about the stranger's motives and knowledge. Similarly, an endorsement from someone you know is less likely to be helpful if you don't know her relationship to the issue about which you are to make a choice. The endorser may, for example, be ignorant of the consequence of your choice. If, however, you know that the endorser shares your interests with regard to the issue and is knowledgeable about its consequences for you, then a triangular operation of the form "If she is voting for X, then I should too" can induce an otherwise incompetent voter to cast the same vote she would have cast if she had, say, the most accurate available information about its consequences. How much information is required depends in large part on the circumstances in which the choice is made. The conditions under which voters can use endorsements to cast competent votes are easier to satisfy when circumstances clarify an endorser's knowledge and incentives for revealing what they know truthfully (Lupia and McCubbins 1998). The impact of any particular proxy will also be a function of what the voter already knows. As Converse (1975: 97) recognized, "the richness and meaning of new information depends vitally on the amount of past information one brings to the new message."

Such dynamics imply that a proxy that is sufficient for one person to vote competently need not be sufficient for another. They also imply that different kinds of 
tasks require different kinds of proxies. Such nuances continue to elude writers who make grand proclamations about voter incompetence or, in particular, the universal inadequacy of heuristic (proxy-based) decision making. The right question to ask is not whether heuristics always (or never) yield competent decisions, because we know that the answer is no. The right question to ask is about the conditions under which use of particular proxies is necessary or sufficient for competent voting. When the literature shifts its emphasis accordingly, it will be on a more credible footing for understanding voter competence and helping to improve it.

I close with a description of conditions under which certain kinds of proxies can aid voter competence. As the kinds of proxies that are most effective vary by electoral context, so do the kinds of survey questions needed to assess competence in that context. The simplest kind of decision is a single binary choice. In such cases, a proxy simply needs to convey which of the two options is better.

What about more complex decisions? Suppose, for example, one wants to label a voter competent only if they make competent choices in every one of a large number of referendums and/or two-candidate elections. If competence is measured with respect to a voter's performance in $\mathrm{N}$ elections, then there are $2^{\mathrm{N}}$ possible choices. For two elections, the first posing a choice between candidates $\mathrm{a}$ and $\mathrm{b}$ and the second being between candidates $\mathrm{c}$ and $\mathrm{d}$, the voter can make four possible decisions: vote for a and $\mathrm{c}, \mathrm{a}$ and $\mathrm{d}, \mathrm{b}$ and $\mathrm{c}$, or $\mathrm{b}$ and $\mathrm{d}$. When the basis of the evaluation is 20 two-candidate elections, then the number of choices is $1,048,576$. For 30 elections, there are over a billion possible combinations of votes to cast. 
If one wants to judge a voter's competence by her performance in all of 20 or 30 elections, the number of options just described might make it seem extremely unlikely that competence can be obtained - particularly by people who pay little attention to politics. It may also be that a person's inability to answer standard political-knowledge questions is sufficient for us to conclude that she is incapable of accomplishing such a complex task. The presence of proxies, however, should caution us against reaching either conclusion prematurely.

Numerous studies of American politics show that a candidate's partisan identification is a powerful force not only in her electoral fortunes, but also in her likely legislative activities. To the extent that a voter, if very well informed, would always choose a particular kind of candidate across all elections, and to the extent that such choices correspond well to partisan proxies, party cues can engender competent performance even in the complex situations described above. If voting Democratic is the best choice a particular voter can make at any level of government, then simply knowing who the Democrat, and voting accordingly, yields the same outcome as would encyclopedic knowledge of all of the candidates. In the 30 election case, we could say that she chose competently even though she had over a billion options from which to choose. And if the proxy is indeed sufficient for competent performance, evidence that this voter is uninformed or misinformed about some minute detail of a candidate's background or activities need not imply that the voter will vote for the wrong candidate.

That proxies exist does not ensure their competent use. People must know enough to apply the proxy effectively. Moreover, when relatively simple proxies such as party identification are applied to complex problems, such as voting competently in a string of 
20 to 30 elections, the proxies must, paraphrasing Paul Sniderman $(2000,74)$, “cut nature at its joints." In the case of two-candidate elections, where one candidate is a Republican and the other is a Democrat and the proxy links the party label to particular political outcomes in the way that complete information would, the proxy can suffice. But as the situation diverges from that description, relying on the simple binary proxy is more hazardous. The binary proxy "Democrat," for example, is not helpful in distinguishing among the candidates in a Democratic primary, and may be of limited help in an electoral context with three or more viable parties. In the extreme, where partisan cues provide no reliable information about what the voter would choose if she were very well informed, evidence that the voter knows a candidate's party identification offers no evidence about her competence (although it should be said that such a circumstance does not increase the reliability of conventional political knowledge questions for assessing civic competence; they may too be completely uninformative).

That proxies can allow people with limited information to vote competently does not imply that ignorance is desirable, but it does imply that concrete progress in assessing and improving political competence can come from more realistic standards than "the fully-informed voter." In the elections upon which voter-competence writers focus most often, "the fully informed voter" is sheer fantasy. Indeed, for most large-scale elections there are two kinds of people: those who realize that they do not know all the relevant facts and those who are deluded enough to think that they do. We cannot know everything about most of the political phenomena we encounter.

Even if "all the facts" could be delivered to citizens, questions would remain about the social value of doing so, for there are many kinds of information on which most 
citizens cannot act. What matters more is the conditions under which they can make effective choices about what information to attend to (Lupia and McCubbins 1998). This idea is key to generating assessments of competence that are more useful to the voters being evaluated and more valuable to the societies of which they are a part.

In everyday life, people base choices not on all of the information they encounter, but on a select subset of it. So even if we could convey "all the facts" to a voter, they would have to process the information and, in the end, some of the facts would turn out to be irrelevant to their decisions. If it is costly to acquire information and if it requires effort to process and remember it, then knowing everything is superfluous, at best.

What you need to know depends on what you have to do. Different citizens have different civic responsibilities. Those citizens who have greater civic ambitions should perhaps know more than those who want merely to vote. Societies do well to invest in their futures and offering civic information to real and potential leaders is important. However, such business is too important to be the product of a narrow worldview. In a mass democracy, it is too important to be based on elitist assumptions.

It is also worth remembering that the more we demand of people, the less freedom they have, and freedom is among the most valuable products that democratic societies can produce. It is imperative, therefore, to join the emphasis on well-informed citizens with realistic evaluations of whether the sacrifices that being well informed entail generate tangible benefits. Voter-competence reformers should minimize the burden on 
citizens whenever possible. Among these burdens are the psychic cost of inadequacy and the social cost of withdrawal when people falsely believe that they have nothing to contribute to civic life because they are comparing themselves to the unrealistic icon of the perfectly informed citizen.

Unless competent performance requires that the task be performed in a particular way, society does not benefit from attempts to regulate how people approach the task. If one person achieves competence in ways that are foreign or unfamiliar to another, and if the unfamiliar way of performing the task does not hurt anyone else, then the person in question should be free to choose that way. She should not have to alter her practices because they do not fit an elitist worldview. Until critics can offer a transparent, credible, and replicable explanation of why a particular set of facts is necessary for a particular set of socially valuable outcomes, they should remain humble when assessing the competence of others. 


\section{REFERENCES}

Bennett, Stephen E. “Know-Nothings Revisited: The Meaning of Political Ignorance Today." Social Science Quarterly 69: 476-92.

Campbell, Angus, Philip Converse, Donald Stokes, and Warren Miller. 1960. The American Voter. New York: John Wiley.

Converse, Philip E. [1964] 2006. “The Nature of Belief Systems in Mass Publics.” Critical Review 18(1-2): 1-**.

Converse, Philip E. 1975. "Public Opinion and Voting Behavior." In Handbook of Political Science," ed. Fred I. Greenstein and Nelson W. Polsby. Reading, Mass.: Addison-Wesley.

Delli Carpini, Michael X., and Scott Keeter. 1996. What Americans Know About Politics and Why It Matters. New Haven: Yale University Press.

Gould, Stephen J. 1996. The Mismeasure of Man, rev. ed. New York: W.W. Norton. Herbert, Bob. 2004. "Voting Without the Facts." The New York Times, November 8: A23.

Kuklinski, James H., and Paul J. Quirk. 2001. “Conceptual Foundations of Citizen Competence.” Political Behavior 23: 285-311.

Lodge, Milton, and Charles Taber. 2000. “Three Steps Toward a Theory of Motivated Political Reasoning.” In Lupia et al. 2000.

Lupia, Arthur. 2005a. "Necessary Conditions for Increasing Civic Competence: A Scientific Perspective.” Book chapter presented at World Bank workshop on "Politics and Service Delivery: When Do Governments Fail Voters?" and at the 
annual meeting of the American Association for the Advancement of Science, Washington D.C.

Lupia, Arthur. 2005b. "Questioning Our Competence: Improving the Relevance of Common Political Knowledge Measures.” Book chapter presented at the annual meeting of the Midwest Political Science Association, Chicago, and the annual meeting of the International Society for Political Psychology.

Lupia, Arthur, and Mathew D. McCubbins. 1998. The Democratic Dilemma: Can Citizens Learn What They Need to Know? New York: Cambridge University Press.

Lupia, Arthur, Mathew D. McCubbins, and Samuel L. Popkin, eds. 2000. Elements of Reason: Cognition, Choice and the Bounds of Rationality. New York: Cambridge University Press.

Newell, Allen. 1990. Unified Theories of Cognition. Cambridge, Mass.: Harvard University Press.

Popkin, Samuel L. 1991. The Reasoning Voter: Communication and Persuasion in Presidential Campaigns. Chicago: University of Chicago Press.

Somin, Ilya. 1998. "Voter Ignorance and the Democratic Ideal." Critical Review 12: 41358.

Somin, Ilya. 2004. “When Ignorance Isn’t Bliss: How Political Ignorance Threatens Democracy." Cato Institute Policy Analysis 525. September 22.

Sniderman, Paul M. 2000. "Taking Sides: A Fixed Choice Theory of Political Reasoning." In Lupia et al. 2000. 


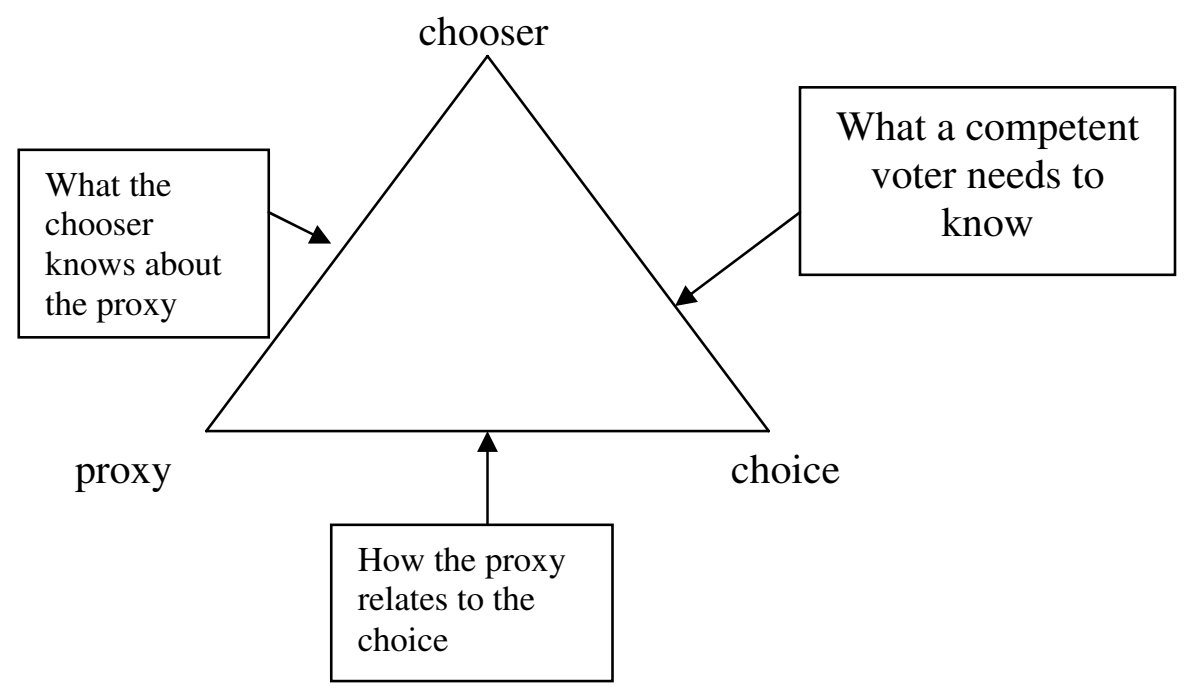

Figure 1. Learning from proxies 